\title{
Myrsinaceae da APA de Cairuçu, Parati (Rio de Janeiro, Brasil)
}

\author{
Sigrid L. Jung-Mendaçolli ${ }^{1}$ \\ Luís Carlos Bernacci ${ }^{2}$
}

\begin{abstract}
RESUMO
A Área de Proteção Ambiental de Cairuçu, localiza-se no município de Parati, Rio de Janeiro, Brasil (23 $10^{\prime}-23^{\prime} \mathrm{S}$ e $44^{\circ} 30^{\prime}-51^{\prime} \mathrm{W}$ ) e apresenta uma área de 33.800 ha, situada na vertente oceânica da Serra do Mar, além de uma parte insular com 63 ilhas. O clima é mesotérmico, superúmido com pouco ou nenhum déficit hídrico. São apresentados os resultados de estudo florístico realizado com as Myrsinaceae nativas da região, representadas pelos gêneros Cybianthus Mart. (2 espécies), Rapanea Aubl. (4 espécies) e Ardisia Swartz (2 espécies).
\end{abstract}

Palavras-chave: Myrsinaceae, Parati, Ardisia, Cybianthus, Rapanea.

\begin{abstract}
The Cairuçu environmental protection area (APA - Cairuçu) is located south of Parati, Rio de Janeiro, Brazil $\left(23^{\circ} 10^{\prime}-23^{\circ} 23^{\prime} \mathrm{S} ; 4^{\circ} 30^{\prime}-44^{\circ} 51^{\prime} \mathrm{W}\right)$ and presents a continental area of 33.800 ha, situated on the oceanic slopes of the "Serra do Mar" having an insular region with 63 islands. Climate is mesothermic, superhumid. Results of floristic survey carried out on native Myrsinaceae of the region proved the occurrence of three genera comprising two species of Cybianthus Mart., four species of Rapanea Aubl. and two species of Ardisia Swartz.
\end{abstract}

Key words: Myrsinaceae, Parati, Ardisia, Cybianthus, Rapanea.

\section{INTRODUÇÃO}

A Área de Proteção Ambiental (APA) Cairuçu, localiza-se no município de Parati, Rio de Janeiro, Brasil, entre os paralelos de $23^{\circ} 10^{\prime}$ e $23^{\circ} 23^{\prime} \mathrm{S}$ e os meridianos de $44^{\circ} 30^{\prime}$ e $44^{\circ} 51^{\prime}$ 'W. Esta unidade de conservação apresenta uma área continental de 33.800 ha situada na vertente oceânica da Serra do Mar, além de uma parte insular com 63 ilhas (Marques, 1997). O relevo é bastante acidentado, variando desde ondulado, montanhoso a escarpado; as áreas planas são reduzidas e representadas por faixas estreitas de várzeas e manguezais. As praias e cordões arenosos são igualmente escassos, sendo o litoral em geral rochoso e escarpado recortado por muitas pequenas enseadas. A altitude na área oscila entre 0 e $1320 \mathrm{~m}$. A hidrografia é a normalmente observada em regiões montanhosas, com forte declividade que é atenuada nas proximidades do litoral (Marques, 1997). O clima, segundo a FIDERJ (1978, apud Marques, 1997), é mesotérmico, superúmido com pouco ou nenhum déficit hídrico.

Na APA - Cairuçu são encontrados os seguintes tipos de vegetação, em ordem de importância: Floresta Ombrófila Densa; Mata Secundária ou Floresta Secundária; Afloramento e/ou Costões Rochosos; Vegetação com Influência Fluviomarinha (Manguezal); Vegetação com Influência Marinha (Restingas), que cobrem cerca de $80 \%$ da área. Existem também áreas de agricultura, praias e núcleos urbanos, representados pela cidade de Parati e Condomínio Laranjeiras (Marques, 1997).

${ }^{1}$ Pesquisadora Científica-VI. Instituto Agronômico. Caixa Postal 28, 13001-970, Campinas, SP. Brasil. Tel.: (19) 3231-54-22 r.178. e-mail: jungmend@iac.br

${ }^{2}$ Pesquisador Científico-III. Instituto Agronômico. Caixa Postal 28, 13001-970, Campinas, SP. Brasil. Tel.: (19) 323154-22 r. 178. e-mail: bernacci@iac.br 
Após a realização da Flora Brasiliensis, quando Miquel (1856) estudou a família, poucos trabalhos envolvendo as espécies de Myrsinaceae nativas do Rio de Janeiro foram efetuados. Mez (1902) realizou os estudos mais abrangentes abordando as Myrsinaceae conhecidas até a ocasião, descrevendo várias espécies, inclusive para o Rio de Janeiro. Os estudos posteriores tiveram abrangências mais restritas e poucas revisões foram realizadas.

Entre os gêneros ocorrentes no Rio de Janeiro apenas para Cybianthus existem revisões. Pipoly $(1981,1983,1987)$ vem abordando a taxonomia do gênero, realizando estudos para os subgêneros, tendo como uma das finalidades subsidiar a futura monografia para a Flora Neotropica. Siqueira (1993) estudou as espécies de Rapanea da região serrana do Rio de Janeiro. Jung-Mendaçolli \& Bernacci (1997a) listaram as Myrsinaceae da APA Cairuçu. Freitas \& Kinoshita (1999) estudaram as Myrsinaceae de Macaé de Cima. Bernacci \& Jung-Mendaçolli (2000) estudaram espécies de Ardisia do sudeste brasileiro, incluindo espécies do Rio de Janeiro.

Dentre as contribuições mais significativas para a taxonomia ou filogenia das Myrsinaceae, também podem ser destacadas aquelas devidas a Lundell (1971), Smith (1973), Agostini (1980), Pipoly (1991, 1992a, b e c), Anderberg \& Ståhl (1995), Pipoly (1996), Ståhl (1997), Pipoly (1998) e Pipoly \& Ricketson (1999). Cronquist (1981) e Judd et al. (1999) também discutem as relações filogenéticas de Myrsinaceae com outras famílias.

Com o intuito de possibilitar o efetivo conhecimento da vegetação da APA - Cairuçu, foi iniciado um projeto sob a coordenação da Dra. Maria do Carmo Mendes Marques (Instituto de Pesquisas Jardim Botânico do Rio de Janeiro), que até o momento resultou na publicação do mapeamento da cobertura vegetal e listagem das espécies, incluindo 807 táxons de dicotiledôneas, pertencentes a 97 famílias (Marques, 1997), e na publicação de monografias para 60 famílias, incluindo 468 táxons ocorrentes no local (Marques, Vaz \& Marquete, 1997). Complementando os trabalhos já publicados apresentaremos os resultados obtidos na família Myrsinaceae, de acordo com o modelo utilizado em Marques, Vaz \& Marquete (1997).

\section{MATERIAL E MÉTODOS}

As atividades do levantamento florístico foram, segundo Marques (1997), subdivididas em três etapas: trabalhos de campo, herbário e laboratório. A de campo foi efetuada de novembro de 1989 a dezembro de 1995 , totalizando 26 expedições de 5 a 10 dias cada. O material botânico foi coletado em vários pontos de amostragem, processado segundo as técnicas usuais de herborização e incluído no Herbário do Jardim Botânico do Rio de Janeiro (RB). Em seguida os materiais foram distribuídos aos especialistas, ocorrendo a doação de duplicatas, quando existentes, para a realização dos trabalhos de laboratório: identificação ou confirmação e descrições. O sistema de classificação adotado para as Angiospermas foi o de Cronquist (1968), respeitando-se as modificações efetuadas pelos especialistas (Marques, 1997).

Foi preparada chave dicotômica para distinção das espécies de Myrsinaceae encontradas na APA - Cairuçu; apresentouse a "obra princeps" e o basiônimo. Os nomes vulgares e utilidade das plantas foram investigados. As espécies foram analisadas em relação ao período de floração e frutificação, distribuições gerais e ambientes de ocorrência na APA - Cairuçu, para possibilitar comparações entre elas e com dados disponíveis de áreas próximas (inclusive de São Paulo). Os materiais examinados foram listados, incluindo-se materiais adicionais selecionados, utilizados para complementar as descrições, buscando-se analisar ao menos dois materiais de cada estádio fenológico, inclusive dois indivíduos de cada sexo, 
quando fosse o caso. Foram preparadas ilustrações de duas espécies, que foram escolhidas dentre aquelas mais abundantes na área, com materiais em boas condições para análise e não freqüentemente ilustradas.

\section{RESULTADOS}

As Myrsinaceae apresentam-se caracteristicamente como arbustos ou árvores de folhas simples, alternas, geralmente com pontuações glandulares e/ou canais resiníferos; pecíolo canaliculado. Inflorescências terminais ou axilares, glomeriformes, umbeladas, racemos ou corimbo simples até panícula de corimbos. Flores 4-5-meras, unissexuadas ou bissexuadas, simetria radial; cálice e corola parcialmente soldados, superfície dos lobos com glândulas vinosas a ocráceas, arredondadas, alongadas ou lineares, às vezes ausentes; estames 4-5, opostos às pétalas, filetes total ou parcialmente soldados à corola e no último caso, formando ou não anel basal, anteras rimosas, dorsifixas; ovário súpero, 1locular, multiovulado, placenta carnosa, central livre. Fruto drupa. Semente 1.

Na APA - Cairuçu, as Myrsinaceae estão representadas por 8 espécies: Cybianthus peruvianus (A.DC.) Miq., Cybianthus sp., Rapanea ferruginea (Ruiz \& Pav.) Mez, $R$. guyanensis Aubl., R. lineata Mez, $R$. parvifolia (A.DC.) Mez, Ardisia depauperata (Mez) Bernacci \& JungMendaçolli e A. martiana Miq.

\section{Chave para identificação dos gêneros e suas respectivas espécies da APA - Cairuçu}

1. Inflorescência laxa, racemo ou corimbo simples até panícula de corimbos.

2. Corimbo simples até panícula de corimbos I. Ardisia

3. Flor 4-mera (excepcionalmente 5-mera, na mesma planta); lâmina com nervação conspícua (constituindo nervura coletora) 1.A. depauperata

3. Flor 5-mera; lâmina com nervação inconspícua 2. A. martiana

2. Racemo, às vezes com a base um pouco ramificada II. Cybianthus

4. Lobos da corola eretos; lâmina foliar cartácea, face dorsal densamente revestida por pêlos lepidotos ferrugíneos, conferindo esta coloração à mesma 3. C. peruvianus

4. Lobos da corola patentes; lâmina foliar membranácea; face dorsal com pontuações dispersas 4. Cybianthus sp III. Rapanea

1. Inflorescência congesta, glomeriforme ou umbelada 5. R. guyanensis

5. Flor pistilada séssil

6. R. ferruginea

6. Folhas e ramos ocráceo-tomentosos

6. Folhas e ramos glabros.

7. Lâmina foliar até $6,1 \mathrm{~cm}$ compr., subcoriácea, obovada, ápice rotundado ou emarginado, canais resiníferos dispersos; estigma inteiro, piramidal (na flor pistilada)

7. $R$. parvifolia

7. Lâmina foliar $6,4 \mathrm{~cm}$ compr. ou mais, membranácea, oblanceolada, ápice agudo, canais resiníferos ordenados em linhas, estendendo-se, desde a nervura mediana, em ângulo menor que o das nervuras secundárias, até a margem; estigma 3-fido, estreitamente cônico verrucoso (na flor pistilada) 


\section{Descrição das espécies}

1. Ardisia depauperata (Mez) Bernacci \& Jung-Mendaçolli, Acta bot. bras. 14(3):245. 2000.

Basiônimo: Stylogyne depauperata (Mart.) Mez, in Engler, Das Pflanzenreich 4. 236 (9): 277. 1902.

Arbusto a árvore, 3,5-6,0m alt.; ramos 2,33,7 mm diâm., glabros. Pecíolo 0,8-1,9 cm compr.; lâmina (10,4-) 12,2-23 cm compr., (3,9-) 5,6-10,4 cm larg., cartácea a coriácea, glabra, elíptica a oval-lanceolada, base aguda a obtusa, ápice obtuso a rostrado, nervura mediana saliente na face dorsal e impressa na ventral, nervação secundária e terciária conspícua em ambas as faces, especialmente na ventral, constituindo nervura coletora, pontuações e canais resiníferos densamente distribuídos, particularmente nas folhas mais tênues. Inflorescência (0,6-) 1,5-2,5 cm compr., (0,7-) 1,5-3,0 $(-3,5) \mathrm{cm}$ larg., axilar ou terminal, corimbo simples ou composto, glabra. Flores 4(-5)-meras, unissexuais ou bissexuais, pedicelos 3,0-6,5 mm compr., glabros. Flor estaminada: cálice ca. 2,0 mm compr., glabro, 1/10 unido, lobos ca. 1,8 mm compr., 2,0 mm larg., largo-ovais, ápice arredondado; corola ca. 4,8 mm compr., glabra, creme, $1 / 4$ unida, lobos ca. 3,6 mm compr., 2,2 mm larg., deflexos, elípticos a oblongo-elípticos, ápice assimetricamente lobado-arredondado; anel estaminal ausente, filete ca. $2,1 \mathrm{~mm}$ compr., anteras 3,0 mm compr., sagitadas; pistilódio (0,1-) 2,5 mm compr., 0,5 mm larg, cônico ou discóide. Flor bissexual: cálice ca. 1,2 mm compr., glabro, 1/10 unido, lobos ca. 1,0 mm compr., 1,0 mm larg., oblongos, ápice arredondado; corola ca. 3,3 $\mathrm{mm}$ compr., glabra, creme, 1/4 unida, lobos ca. 2,8mm compr., 1,7 mm larg., deflexos, oblongos, ápice assimetricamente lobado-arredondado; anel estaminal ausente, filete 1,5-2,7 mm compr., anteras 1,7 mm compr., sagitadas; ovário 1,2-1,5 mm compr., 0,5-1,0 mm larg., oval a elíptico; estilete 1,8-2,1 mm compr.; estigma punctiforme, truncado. Fruto 8,8-10,3 mm compr., 8,8-10,3 mm diâm., arredondado-apiculado, ainda imaturo; semente 6,6-7,8 mm compr., 6,6-7,8 mm diâm., arredondada.

Dados fenológicos, ecológicos e de distribuição: Na APA - Cairuçu foi coletada em flor em novembro. A espécie é referida para o Rio de Janeiro e São Paulo.

Comentários: Mez (1902) não designou o holótipo da espécie, sendo que o material Glaziou 14046 (RB), por nós examinado, é um de seus síntipos. Na listagem preliminar da APA - Cairuçu, a espécie foi referida, por JungMendaçolli \& Bernacci (1997), como Stylogyne depauperata Mez.

Material examinado: APA - Cairuçu: Picada em beira de estrada, $\mathrm{Km}$ 0, na divisa RJ-SP, 22.XI.1990, M.Nadruz 658 et al., fl. masc. (IAC, RB).

Material adicional examinado: Rio de Janeiro: Serra da Bica, perto de Cascadura, 10.XII.1882, Glaziou 14046, fl. masc. (RB). São Paulo: Caraguatatuba, Reserva Florestal, 25.V.1966, J.Mattos 13766, fr. imat. (SP); Ilha Bela, 27.III.1971， J.Mattos 15749 \& N.Mattos, fl. bis. (SP).

2. Ardisia martiana Miq., in Mart., Fl. bras. 10:285. t. 30. 1856.

Arvoreta ou árvore a arbusto (5,0-) 6,0-9,0 $(-10,0) \mathrm{m}$ alt.; ramos 3,4-4,8 $(-5,0)$ mm diâm., glabros. Pecíolo 1,5-2,0 cm compr.; lâmina (10,9-) 12,1-18,2 (-20,0) cm compr., (4,1-) 6,1-7,6(-9,2) cm larg., cartácea, glabra, elíptico-ovada a elípticoobovada, base obtusa, ápice arredondado, curta e obtusamente rostrado, nervura mediana saliente na face dorsal e impressa na ventral, nervação secundária e terciária inconspícua em ambas as faces, especialmente na dorsal, pontuações e canais resiníferos densamente distribuídos. Inflorescência ca. 12,0 cm compr., 11,5 cm larg., terminal, panícula de corimbos, glabra. Flores 5meras, bissexuais, pedicelos 2,5-5,0 mm compr., glabros; cálice ca. 2,2 mm compr., glabro, 1/2 unido, lobos ca. 1,1 mm compr., 0,8 mm larg., oblongos a obovados, ápice assimetricamente lobado-arredondado; corola ca. 4,0 mm compr., glabra, creme, 1/4 unida, lobos oblongos, ca. 3,0mm compr., 1,3mm larg.; anel estaminal 
ausente, filetes ca. 2,0 mm compr., anteras ca. 1,9 mm compr., oblongas; ovário ca. $1,0 \mathrm{~mm}$ compr., 0,4 mm larg., cilíndrico, estilete ca. 2,3 mm compr., cilíndrico, estigma punctiforme, capitado. Fruto ca. 6,2 mm alt., 7,7 mm diâm., oblato, roxo a nigrescente; semente ca. $4,4 \mathrm{~mm}$ alt., 6,7 mm diâm., oblata.

Dados fenológicos, ecológicos e de distribuição: Observada em flor em agosto e em fruto em março. Ocorre no Rio de Janeiro e São Paulo e habita a Floresta Ombrófila Densa a ca. 290 m s. m., sendo semi-ciófila até heliófila ou ciófila, na APA-Cairuçu.

Comentários: A espécie foi referida por JungMendaçolli \& Bernacci (1997a) comoStylogyne laevigata (Mart.) Mez, entretanto, o nome válido para a espécie é Ardisia martiana Miq. (Bernacci \& Jung-Mendaçolli, 2000). Icacorea laevigata Mart., utilizado como basiônimo de $S$. laevigata, por Mez (1902), é umnomem nudum, não tendo sido efetivamente publicado, e quando Miquel (1856) descreveu A. martiana citou-o como sinônimo.

Material examinado: APA - Cairuçu: Estrada Parati-Cunha, entre Km 15 e 16, próximo ao rio, 16.III.1989, A.L.Almeida 10 et al., fr. (IAC, RB); margem do rio Corisco, 22.VIII.1995, A.Castellar 10 et al., fl. (IAC, $\mathrm{RB}) ; 2^{\circ}$. Distrito, córrego dos Micos, trilha para o morro da Pedra Rolada, 290m s.m., em afloramento rochoso, 23.VIII.1995, L.C.Giordano 2026 et al., fl. (IAC, RB); trilha para o morro do Cuscuzeiro, 10.VIII.1994, C.Duarte 96 et al., fl. (IAC, $\mathrm{RB})$.

Material adicional selecionado: São Paulo: Ubatuba, Picinguaba, 23 18 ' 09' S, 44 48' 61" W, 13.III.1997, M.Sanchez 1569 et al. fr. (IAC, UEC).

3. Cybianthus peruvianus (A.DC.) Miq., in Mart,. Fl. Bras. 10:298. 1856.

Basiônimo: Conomorpha peruviana A.DC., Ann. Sci. Nat., sér. 2, 16: 92. 1841.

Figs. 1 - 5.

Arbusto a árvore (2,0-) 2,5-8,0 (-12,0)m alt.; ramos (1,6-) 1,7-2,4 (-2,5)mm diâm., lepidoto-ferrugíneos quando novos, glabrescentes a glabros depois. Pecíolo (0,5-) 0,7-0,9 (-1,2)cm compr.; lâmina (4,6-) 5,2-6,6 $(-9,0) \mathrm{cm}$ compr., (1,5-) 1,7-2,1 (-3,9)cm larg., cartácea, pilosidade densamente lepidotoferrugínea na face dorsal, conferindo esta coloração à mesma, esparsamente na ventral, oboval, elíptica, lanceolada, oblonga ou oval, base aguda a obtusa, ápice abruptamente acuminado, nervura mediana saliente na face dorsal, impressa na ventral, nervação secundária inconspícua na face dorsal, tênue na ventral, terciária inconspícua em ambas as faces, pontuações não visíveis. Inflorescência (1,1-) 2,1-2,8 (-4,0)cm compr., (0,6-) 0,7-1,3 ($4,2) \mathrm{cm}$ larg., axilar, racemo, às vezes com a base um pouco ramificada, ferrugíneo-lepidota. Flores 4-5-meras, unissexuadas; pedicelo 1,82,1 (-2,2)mm compr., ferrugíneo-lepidoto. Flor estaminada: cálice ca. 1,1mm compr., glabro, $1 / 3$ unido, lobos ca. $0,8 \mathrm{~mm}$ compr., $0,6 \mathrm{~mm}$ larg., triangulares, ápice agudo; corola ca. $2,5 \mathrm{~mm}$ compr., glabra, creme, 1/2 unida, lobos ca. 1,3mm compr., 1,0mm larg., eretos, oblongolanceolados, ápice agudo; anel estaminal presente, ca. $1,5 \mathrm{~mm}$ compr., porção livre do filete ca. $0,6 \mathrm{~mm}$ compr., antera ca. $0,8 \mathrm{~mm}$ compr., sagitada; pistilódio ca. $1,3 \mathrm{~mm}$ compr., cônico. Flor pistilada: cálice ca. 1,0mm compr., glabro, $1 / 2$ unido, lobos ca. $0,5 \mathrm{~mm}$ compr., $0,5 \mathrm{~mm}$ larg., triangulares, ápice agudo; corola ca. $1,8 \mathrm{~mm}$ compr., glabra, creme, $1 / 2$ unida, lobos ca. $0,9 \mathrm{~mm}$ compr., $0,9 \mathrm{~mm}$ larg., eretos, oblongos, ápice agudo; anel estaminodial presente, ca. 1,0mm compr., porção livre do filete ca. $0,1 \mathrm{~mm}$ compr., antera vestigial ca. $0,5 \mathrm{~mm}$ compr., sagitada; ovário ca. $0,5 \mathrm{~mm}$ alt., $0,5 \mathrm{~mm}$ diâm., esférico, estilete ca. $0,5 \mathrm{~mm}$ compr., cilíndrico, estigma subcapitado. Fruto, ca. 4,0mm alt., 5,0mm diâm., oblato, escuro; semente ca. 3,1mm alt., 4,5mm diâm., oblata. Nomes vulgares: Capororoca (Smith \& Downs, 1957; Fonnegra-Gómez, 1985), garapaca-punta (Mez, 1902; Corrêa, 1931).

Utilidades: Fornece madeira para obras internas, lenha e carvão (Corrêa, 1931). 

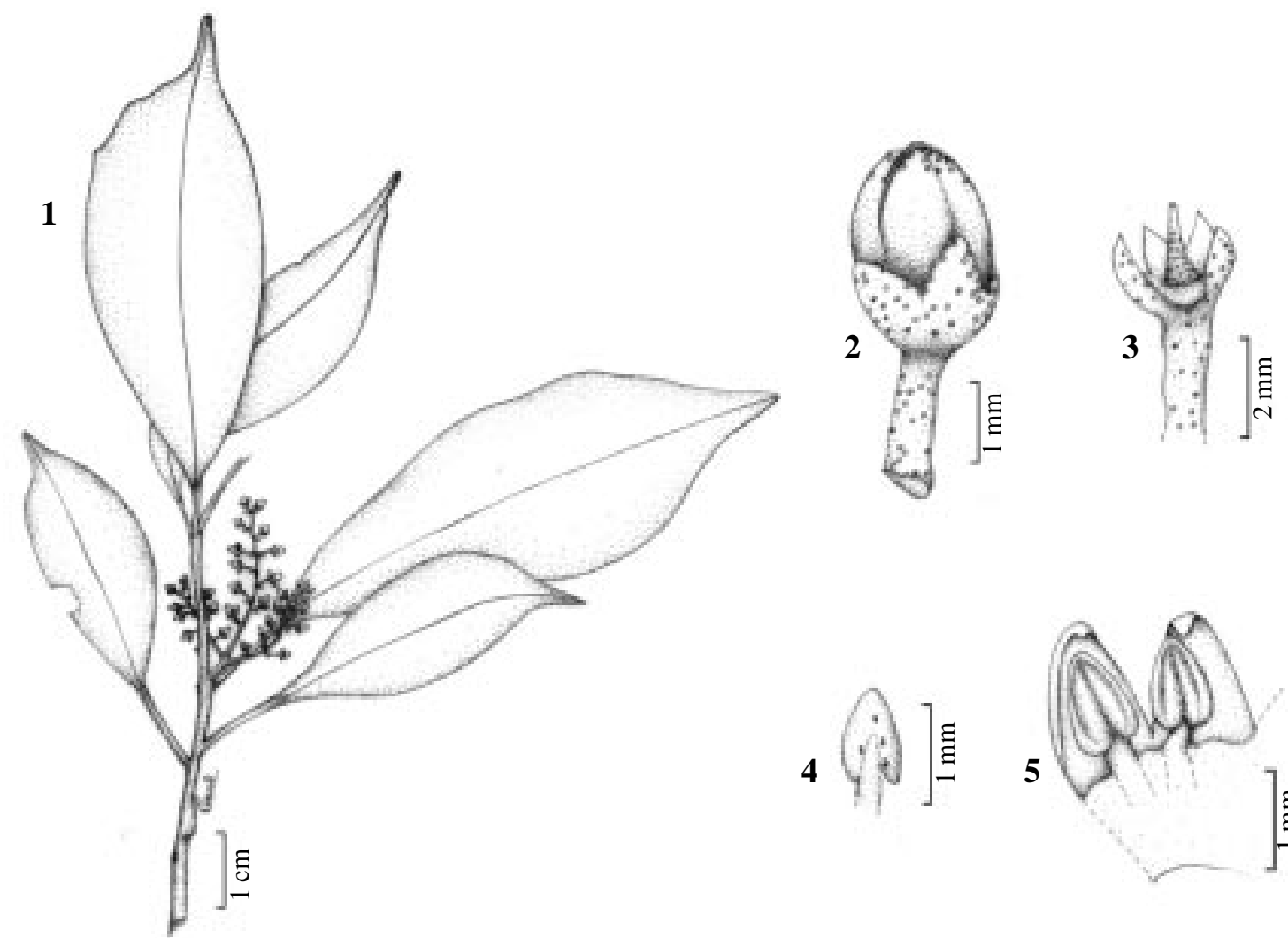

4
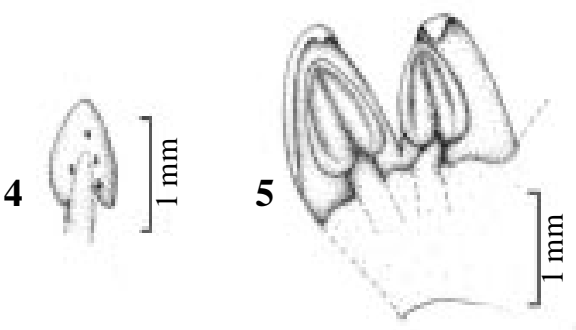

Figuras 1 - 5. Cybianthus peruvianus (A. DC.) Mez. 1. Aspecto geral de ramo com inflorescência. 2. Detalhe do botão floral. 3. Detalhe da flor evidenciando o pistilódio. 4. Detalhe do estame evidenciando antera em vista dorsal e inserção da porção livre do filete. 5. Detalhe da corola evidenciando anteras em vista ventral, porção livre dos filetes e o anel estaminal.

Dados fenológicos, ecológicos e de distribuição: Observada com flores em março e abril. Ocorre de 60-1200 m s.m. de altitude, sendo semi-ciófila a heliófila. Distribui-se pela Venezuela até Bolívia, sul e sudeste do Brasil. Comentários: Mez (1902), distinguiu os gêneros Conomorpha e Cybianthus e considerou que Cybianthus peruvianus (A. DC.) Miq. pertenceria ao gênero Conomorpha, reconhecendo quatro variedades: Conomorpha peruviana Mez var. peruviana, C. peruviana var. guyanensis (A. DC.) Mez, C. peruviana var. rostrata (Hassk.) Mez e C. peruviana var. brasiliensis Mez. Os espécimes com distribuição em campos e restingas da região sul e central do Brasil representariam $C$. peruvianus var. brasiliensis, que foi caracterizada como tendo lâmina foliar com 3,5 x 2,0 cm e porção livre do filete maior do que a antera. Conomorpha peruviana var. peruviana foi caracterizada por apresentar lâmina foliar com 8,0 x 4,0 cm e porção livre do filete menor do que a antera. Agostini (1980) considerou os gêneros Conomorpha e Cybianthus como indistintos, tratando suas espécies sob o gênero Cybianthus, mantendo Cybianthus peruvianus (A. DC.) Miq. e elevando Conomorpha peruviana var. brasiliensis ao nível de espécie: Cybianthus brasiliensis (Mez) Agostini. No entanto, Agostini (1980) não justificou a elevação ao nível de espécie de $C$. brasiliensis, nem apresentou a relação do material examinado, entre outras informações relevantes. Os espécimes observados em Parati apresentaram lâmina foliar de tamanho intermediário entre $C$. peruvianus e $C$. brasiliensis e 
excepcionalmente sobrepondo-se ao tamanho de $C$. peruvianus em relação ao comprimento, e sobrepondo-se ao tamanho de C. brasiliensis e excepcionalmente aproximando-se ao tamanho de $C$. peruvianus em relação à largura. Na Ilha do Cardoso, litoral sul de São Paulo (Jung-Mendaçolli \& Bernacci, 1997b), o tamanho foliar sobrepôs-se ao de $C$. peruvianus em relação ao comprimento e era intermediário entre esta espécie e $C$. brasiliensis, excepcionalmente sobrepondo-se ao tamanho das duas espécies. Os tamanhos da antera e da porção livre do filete também se mostraram variáveis, considerando-se os espécimes de Parati e da Ilha do Cardoso. $\mathrm{Na}$ Ilha do Cardoso (Jung-Mendaçolli \& Bernacci, 1997b) a porção livre do filete era bem menor $(0,2 \mathrm{~mm})$ do que a antera $(1,0 \mathrm{~mm})$, enquanto em Parati a porção livre do filete $(0,6 \mathrm{~mm})$, embora menor, tinha tamanho próximo ao da antera $(0,8 \mathrm{~mm})$. Devido à inconsistência dos caracteres apontados por Mez (1902), acreditamos não ser possível distinguir $C$. brasiliensis de $C$. peruvianus, devendo ser mantido o último, respeitando-se a prioridade. Mez (1902), não designou o holótipo de Conomorpha peruviana var. brasiliensis, basiônimo de $C$. brasiliensis, sendo que o material Schwake 6990 (RB), por nós examinado é um de seus síntipos.

Material examinado: APA - Cairuçu: Cuscuzeiro, 1200 m s.m., 28.II.1995, M.G.Bovini 731 et al., fl. masc. (IAC, RB); Ponta Negra, Vargem Grande, trilha para a Pedra da Jamanta, 60m s.m., 14.IV.1994, $R$. Marquete 1632, fl. masc. (IAC, RB).

Material adicional examinado: Rio de Janeiro: Maricá, restinga, 16.XI.1890, Schwacke 6990, fl. fem. (RB); Petrópolis, Morro de Carangola, 22.XII.1882, Glaziou 14047, fl. masc. (R). São Paulo: Biritiba-Mirim, Estação Biológica de Boracéia, 890-950m s.m., 06.IV.1984, A.Custódio Filho 2359, fl. fem. (IAC, SP, SPSF); São Miguel Arcanjo, Parque Estadual de Carlos Botelho, 21.IV.1994, P.L.R.Moraes 911 et al., fr. (ESA, IAC).
4. Cybianthus sp.

Arbusto a árvore; ramos 1,5-1,6 mm diâm., lepidoto-ferrugíneos quando novos, glabros a glabrescentes depois. Pecíolo 2,04,0mm compr.; lâmina (7,3-) 7,9-9,6 (-11,4) cm compr., (1,4-) 3,1-3,5 $(-4,1) \mathrm{cm}$, tenuamente membranácea, pêlos lepidotos não ferrugíneos na face dorsal, glabra na ventral, obovadas, base atenuada, truncada a obtusa, ápice longocuspidado, nervura mediana saliente em ambas as faces, nervação secundária conspícua na face dorsal, pouco conspícua na ventral, terciária inconspícua na face dorsal, tênue na ventral, pontuações dispersas. Inflorescência 1,9-4,4cm compr., 0,6-1,2 cm larg., axilar, racemo, ferrugíneo-lepidota. Flor 4-mera, unissexuada, pedicelo 4-5 mm compr., ferrugínolepidoto. Flor estaminada: cálice ca. $2,3 \mathrm{~mm}$ diâm., ciliado, $1 / 5$ unido, lobos ca. $0,8 \mathrm{~mm}$ compr., $0,7 \mathrm{~mm}$ larg., ovais, ápice agudo ou arredondado; corola 5,0mm diâm., ciliada, esbranquiçada, 1/3 unida, lobos ca. 1,9 mm compr., 1,9 mm larg., patentes, oblongos a subcirculares, ápice arredondado; anel estaminal ausente, filete ca. $0,4 \mathrm{~mm}$ compr., antera ca. $0,5 \mathrm{~mm}$ compr., oval; pistilódio ca. 0,6 mm compr., cônico. Flor feminina não vista. Fruto ca. 7,0 mm diâm., 7,0 $\mathrm{mm}$ alt., arredondado, imaturo verde; semente ca. $5 \mathrm{~mm}$ alt., $5 \mathrm{~mm}$ diâm., arredondada.

Dados fenológicos, ecológicos e de distribuição: Coletadoem frutos em abril. Espécie ciófila. Ocorre no Rio de Janeiro e São Paulo.

Comentários: Além do material de Parati, foi possível examinar até o momento, apenas outro (Imamoto s.n., SPSF 13294), coletado em Caraguatatuba, SP. No exemplar de Caraguatatuba as folhas são em geral mais longas e mais largas. Ambos apresentam as folhas tenuamente membranáceas, caracteristicamente adensadas no ápice. A escassez de materiais coletados dificultou a análise e a identificação dos mesmos, mas, estes não têm semelhanças com nenhuma das espécies depositadas nos herbários BAUR, BOTU, ESA, FCAB, FUEL, HB, HRCB, IAC, PMSP, RB, R, SP, SPSF, SPFR e UEC, nem com as descrições de espécies referidas 
na bibliografia disponível. É possível que se trate de uma nova espécie.

Material examinado: APA - Cairuçu: Morro do Carrapato, 200m s.m., 17.IV.1994, R.Marquete 1669, fr. (RB).

Material adicional examinado: São Paulo: Caraguatatuba, Parque Estadual, trilha do Jequitibá, 17.I.1990, M. Imamoto s.n., fl. masc. (SPSF 13284).

5. Rapanea guyanensis Aubl., Hist. Pl. Gui. Franç. 1:46. 1775.

Árvore, eventualmente arvoreta ou arbusto (2,0-) 5,0-20,0 (-25,0) $\mathrm{m}$ alt.; ramos (2,7-) 3,8-5,6 (-7,8) mm larg., glabros. Pecíolo (0,4-) 0,8-1,2 (-1,5) cm compr., glabro, lâmina (6,4-) 9,2-12,5 (-19,9) cm compr., (2,2-) 3,3-4,9 (-6,7) cm larg., obovada, base cuneada, revoluta, ápice arrendondado, nervura mediana saliente em ambas as faces, especialmente na dorsal, nervação secundária inconspícua na face dorsal, tênue na ventral, terciária inconspícua, pontuações dispersas. Inflorescência (0,1-)1,0$1,5 \mathrm{~mm}$ compr., axilar, umbelada a glomeriforme, glabra. Flores 4-meras, unissexuais, pedicelos (0-)1,0-2,0 mm compr., glabros. Flor estaminada: cálice ca. $3,0 \mathrm{~mm}$ compr., glabro, 2/3 unido, lobos ca. 0,9 mm compr., 0,8 mm larg., oval-triangulares, ápice arredondado; corola ca. 2,5 $\mathrm{mm}$ compr., ciliada, creme, 1/5 unida, lobos ca. 2,0 mm compr., 1,0 mm larg., patentes, côncavooblongos, ápice agudo ou levemente arredondado; anel estaminal ausente, antera séssil ca. 1,7 mm compr., unida à pétala nos 2/3 basais, elíptica ou levemente obovada; pistilódio submilimétrico, subésferico, estigma reduzido, cônico. Flor pistilada: cálice ca. 1,1 mm compr., glabro, porção unida submilimétrica, lobos ca. 0,8 mm larg., triangulares, ápice arredondado; corola ca. 3,2 mm compr., ciliada, creme, 1/5 unida, lobos 2,6 mm compr., 1,0 mm larg., patentes ou deflexos, oblongo-lanceolados, ápice agudo; anel estaminoidal ausente, antera vestigial séssil, ca. 1,2 mm compr., oblongo-elíptica; ovário ca. 1,1 mm compr., 0,9 mm diâm., subesférico, glabro, estigma séssil, ca. 1,0 mm compr., 3-laciniado. Fruto ca. 5,5 mm diâm., esférico, vermelho com glândulas vinosas; semente ca. 4,5 $\mathrm{mm}$ alt., 4,2 $\mathrm{mm}$ diâm., arredondada.

Nomes vulgares: Capororoca, capororocacomum, capororoca-de-folha-larga, jacarédo-campo (Corrêa, 1926); mangue-do-mato (etiqueta de herbário).

Utilidades: Segundo Corrêa (1926), fornece madeira branco-acinzentada com tons róseos, resistente, pesada, própria para marcenaria, carpintaria, carroçaria e obras de torno; usada como lenha; a casca é rica em substâncias tânicas, usada na indústria do curtume. Hassler (apud Corrêa, 1926) relata a utilização das folhas desta espécie para a falsificação da erva-mate.

Dados fenológicos, ecológicos e de distribuição: Observada com flores em junho e julho, e com frutos de julho a abril. Espécie encontrada do Rio de Janeiro a Santa Catarina. Heliófila encontrada em restinga (área com influência marinha); também coletada em transição restinga-mata e floresta primária de encosta.

Comentários: Jung-Mendaçollli \& Bernacci (1997b) consideraram que as flores de $R$. guyanensis eram sésseis entretanto houve um equívoco, pois apenas as flores pistiladas, às vezes, o são, tal como observado na APA Cairuçu. As flores estaminadas apresentam pedicelo de 1,0-2,0 $\mathrm{mm}$ compr.

Material examinado: APA - Cairuçu: Restinga do Grumari, restinga, 12.IX.1988, L.C.Giordano 453 \& M. Nadruz, fr. imat. (RB); Ilha das Almas, 15.III.1989, L.C.Giordano 587 et al., fr. imat. (RB); Ilha dos Ratos, 12.IV.1989, L.C.Giordano 640 et $a l$, fr. imat. (RB); Km 206 da rodovia RioSantos ao lado do sítio Canela Amarela, 16.X.1990, V.L.G.Klein 921 et al., fr. (RB). Material adicional selecionado: São Paulo: Cananéia, Ilha do Cardoso: margem do Rio Perequê, 12.VII.1983, J. B. Baitello 102, fl. masc. (IAC, SP, SPF); ibidem, Morro do 
Marujá, 05.VII.1989, F. Barros 1683, fl. masc. (IAC, SP); ibidem, base do Morro Morretes, 22.VIII.1984, M. Kirizawa 1273 et al., fr. (IAC, SP); ibidem, Morro do Marujá, trilha rumo à praia de Lajes, 20.VI.1989, L. Rossi 518 et al., fl. masc. (IAC, SP); ibidem, restinga do Marujá, 22.VII.1981, O.Yano 3719, fl. fem. (SP); São Vicente, Biquinha, 16.VIII.1947, A. B. Joly s.n., fl. fem. (SPF 63842).

6. Rapanea ferruginea (Ruiz \& Pav.) Mez, in Urb., Symb. Antill. 2: 429. 1901.

Basiônimo: Caballeria ferruginea Ruiz \& Pav., Syst.: 250. 1798.

Árvore ou arvoreta (2,5-) 6,0-10,0 (-15,0) m alt.; ramos (1,3-) 1,6-2,1 (-2,5) mm diâm., ocráceotomentosos quando novos, glabrescentes a glabros depois. Pecíolo (4,0-) 6,0-8,0 (-10,0) cm compr., ocráceo-tomentosos; lâmina (5,4-) 7,0-8,7 (-12,5) cm compr., (1,6-) 1,9-2,3 (-2,8) cm larg., membranácea, esparsamente tomentosa a glabra na face dorsal, com pilosidade mais densa ao longo da nervura mediana, glabrescente a glabra na face ventral e esparsos pêlos na nervura mediana, oblanceolada, base aguda revoluta, ápice agudo, raro acuminado, nervura mediana impressa na face dorsal, saliente na ventral, nervação secundária e terciária conspícua, especialmente na face ventral, pontuações dispersas. Inflorescência séssil, axilar, glomeriforme. Flores 4-meras, unissexuais, pedicelo 0,4-0,8 mm compr., glabro. Flor estaminada: cálice ca. $0,9 \mathrm{~mm}$ compr., ciliado, 1/3 unido, lobos ca. $0,7 \mathrm{~mm}$ compr., $0,4 \mathrm{~mm}$ larg., triangulares, ápice agudo; corola ca. 2,8 mm compr., ciliada, esverdeada, 1/3 unida, lobos ca. 1,8 mm compr., 0,8 mm larg., patentes, elípticolanceolados, ápice agudo; anel estaminal ausente, antera séssil ca. 1,0 mm compr., elíptica, unida à pétala no $1 / 3$ basal; pistilódio, ca. $0,5 \mathrm{~mm}$ compr., cônico-rostrado. Flor pistilada: cálice ca. $0,7 \mathrm{~mm}$ compr., ciliado, $1 / 3$ unido, lobos ca. $0,6 \mathrm{~mm}$ compr., $0,5 \mathrm{~mm}$ larg., triangulares, ápice agudo; corola ca. $1,9 \mathrm{~mm}$ compr., $1 / 3$ unida, lobos $1,5 \mathrm{~mm}$ compr., 0,4 mm larg., patentes, oblongo-lanceolados, ápice agudo; antera séssil ca. 0,9 mm compr., sagitada, unida à pétala no $1 / 10$ basal; ovário ca. $1,1 \mathrm{~mm}$ compr., 1,1 mm diâm., esférico, estigma séssil ca. 1,0 mm compr., cônico-verrucoso. Fruto ca. 3,8 mm alt., 4,0 mm diâm., subesférico, vinoso, com pontuações enegrecidas; semente ca. 2,6 mm alt., 3,9 mm diâm., subesférica.

Nomes vulgares: Capororo, caapororocamirim (Hoehne et al., 1941); azeitona-do-mato (Corrêa, 1926).

Utilidades: Os frutos são comestíveis sob a forma de conserva em vinagre (Corrêa, 1926). A importância da espécie na alimentação de pássaros é referida por Siqueira (1993), que incentiva a sua utilização na arborização de ruas e praças.

Dados fenológicos, ecológicos e de distribuição: Espécie observada com flores em abril e maio e com frutos em junho, agosto e outubro. Ocorre em toda a América Tropical, desde o México até a Argentina, com exceção da Guiana, Hiléia e Chile. No Brasil existem citações para os estados da BA, MG, RJ, SP, $\mathrm{PR}, \mathrm{SC}$ e RS. Desenvolve-se em Mata secundária (Floresta Ombrófila Densa, degradada) e Floresta Ombrófila Densa, heliófila a semi-ciófila, ocorrendo de 0-300 m s.m., na APA-Cairuçu.

Comentários: Esta espécie é facilmente reconhecida no campo pela pilosidade ocráceotomentosa, especialmente das partes jovens, que pode variar entre as tonalidades cinzaamarelada a ferrugíneo-avermelhada.

Material examinado: APA - Cairuçu: Ponta Negra, trilha para praia dos antigos, $200 \mathrm{~m}$ s.m., 9.VI.1994, M.G.Bovini 450, fr. (RB); Morro do Corisquinho, $250 \mathrm{~m} \mathrm{s.} \mathrm{m.,} \mathrm{27.VI.1995,} M$. $R$. Campos 31 et al., fr. (RB); estrada para Trindade, $300 \mathrm{~m}$ s. m., 12.IV.1991, L. C. Giordano 1048 et al., bot. (RB); estrada RioSantos, lado esquerdo, próxima à divisa do Estado de São Paulo, 300 m s.m., 13.IV.1991, L.C.Giordano 1070 et al., bot. (RB); Km 206 da estrada Rio-Santos, lado direito do sítio Canela Amarela, 17.X.1990, V.L.G.Klein s.n., fr. (RB 302225); Fazenda do Sr. Gibrail, 29km do trevo de Parati, antiga trilha para o saco de Mamanguá, 27.IV.1993, R.Marquete 844 et al., bot. (RB); Parati-Mirim, Pedra Azul na trilha para Laranjeiras, 240 m s.m., 16.V.1995, 
C. B. Moreira 4 et al., fl. masc. (RB); aproximadamente $13 \mathrm{~km}$ do trevo de Parati, passando a primeira ponte, entrada à direita, subindo o rio Corisco, $430 \mathrm{~m}$ s.m., 29.VI.1993, R.C.C.Reis 24 et al., fr. imat. (RB); estrada para Corisquinho, 340 m s.m., 04.VIII.1994, A.P.S.Ribeiro 32 et al., fr. imat.; (RB), ParatiMirim, Pedra Azul, trilha para Laranjeiras, aproximadamente $240 \mathrm{~m}$ s.m., 16.V.1995, G. M. Silva 3 et al., fl. fem.(RB); ibidem, 16.V.1995, G. M. Silva 5 et al., fr. imat. (RB). Material adicional selecionado: São Paulo: Campo Grande, Estação Biológica, 16.VII.1963, O. Handro 1069, fl. masc. (SPF); Cananéia, Ilha do Cardoso, estrada para o Morro da Captação d'água, 19.III.1986, S.A.C.Chiea 419, fl. fem. (IAC, SP).
7. Rapanea parvifolia (A.DC.) Mez, in Engler, Das Pflanzenreich 4. 236 (9):389. 1902. Basiônimo: Myrsine parvifolia A.DC., Ann. Sc. Nat., sér. 2, 16:87. 1841.

Figs. 6-11.

Arbusto muito ramificado a arvoreta ou árvore, (1,0-) 2,0-3,5 (-7,0) $\mathrm{m}$ alt.; ramos (1,7-) 2,3-3,0 (-3,4) mm diâm., glabros. Pecíolo 0,2-0,4 (-0,5) cm compr.; lâmina (2,9-) 3,4-5,1 $(-6,1)$ cm compr., (1,3-) 1,8-2,4 (-3,2) cm larg., subcoriácea, glabra, obovada, base aguda ou cuneada, ápice rotundado ou emarginado, nervura mediana saliente na face dorsal, impressa na ventral, nervação secundária e terciária incospícuas, pontuações e canais resiníferos dispersos. Inflorescência 6-9 mm compr., axilar, umbelada, glabra. Flor 5-mera,

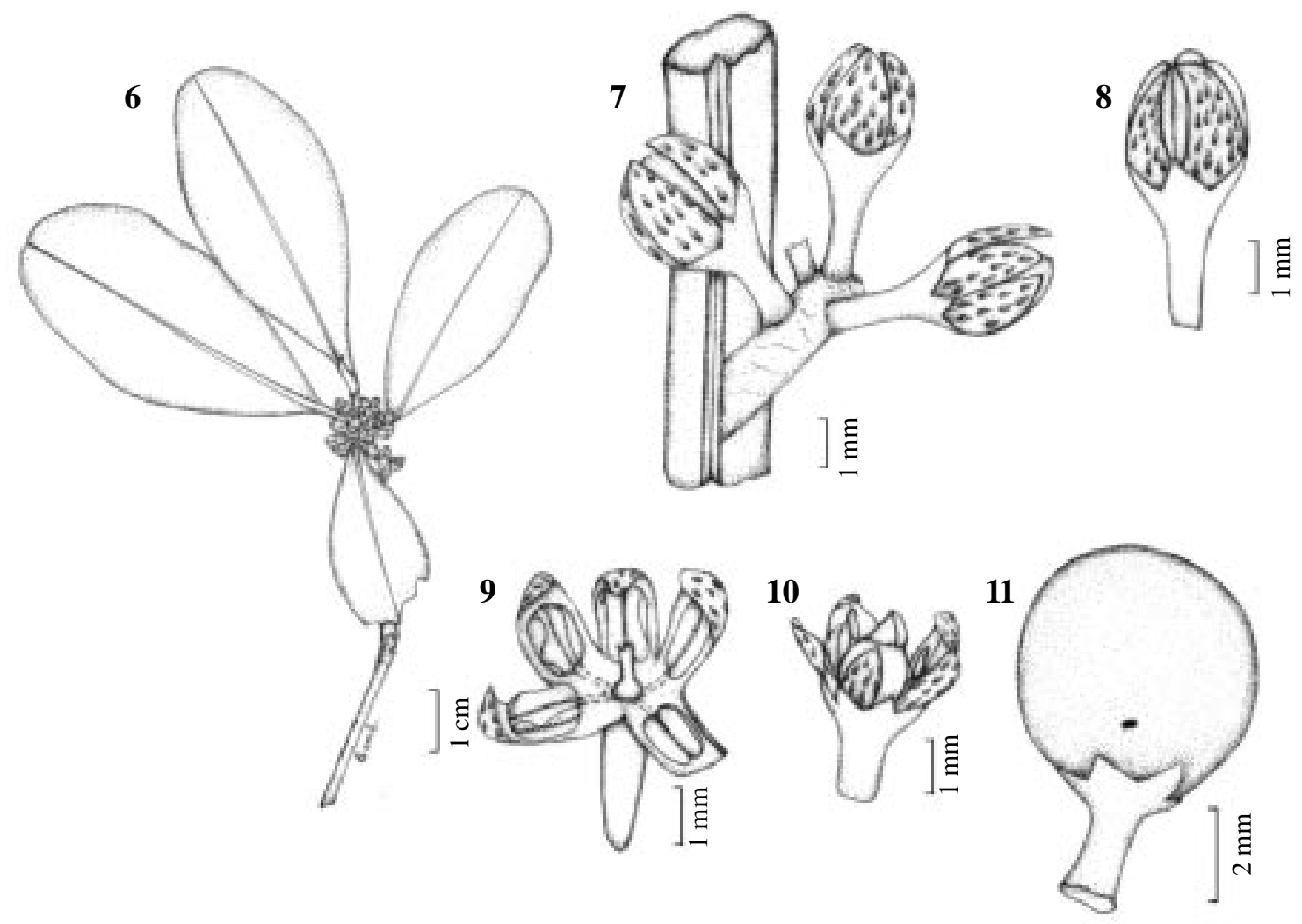

Figuras 6 - 11. Rapanea parvifolia (A.DC.) Mez. 6. Aspecto geral de ramo com inflorescências. 7. Detalhe da inflorescência. 8. Detalhe do botão floral. 9. Flor estaminada evidenciando anteras sésseis e pistilódio. 10. Flor pistilada mostrando ovário, estigma séssil e estaminódio. 11. Fruto. 
unissexuada, pedicelo (2,0-) 2,5-3,0 (-3,5) mm compr., glabro. Flor estaminada: cálice ca. $1,4 \mathrm{~mm}$ compr., ciliado, $1 / 3$ unido, lobos $0,9 \mathrm{~mm}$ compr., 0,9 mm larg., triangulares, ápice agudo; corola ca. 3,9 mm compr., ciliada, esverdeada, 1/4 unida, lobos 2,9mm compr., 0,9 mm larg., patentes, oblongos, ápice agudo; anel estaminal ausente, antera séssil, ca. 2,1 mm compr., unida à pétala na $1 / 2$ basal, oblonga; pistilódio ca. $1,0 \mathrm{~mm}$ compr., estigma reduzido, estreitamente cônico. Flor pistilada: cálice ca. $0,7 \mathrm{~mm}$ compr., ciliado, $1 / 4$ unido, lobos $0,5 \mathrm{~mm}$ compr., $0,7 \mathrm{~mm}$ larg., triangulares, ápice agudo; corola ca. 2,7 mm compr., ciliada, esverdeada, $1 / 4$ unida, lobos 1,9 mm compr., 0,8 mm larg., patentes ou deflexos, oblongos, ápice agudo; anel estaminoidal ausente, antera vestigial séssil, ca. 1,4 mm compr., sagitada; ovário ca. $1,5 \mathrm{~mm}$ compr., 0,8 mm diâm., subcilíndrico, estigma séssil, ca. 1,0 mm compr., inteiro, piramidal. Fruto 4,0-4,5 mm alt., 4,0-4,2 (-4,8) mm diâm., vermelho-escuro a nigrescente; semente 2,32,8 mm alt., 2,7-3,1 mm diâm., oblata.

Nomes vulgares: Capororoca-branca (Corrêa, 1926); capororoca (Smith \& Downs, 1957).

Dados fenológicos, ecológicos e de distribuição: Observada com flores de outubro a dezembro e com frutos em fevereiro, maio, junho e julho. Coletada em mata de encosta e transição mangue-restinga. A espécie ocorre no litoral, desde o Rio de Janeiro até Montevidéu.

Comentários: Segundo Mez (1902) é um arbusto característico de restinga.

Material examinado: APA - Cairuçu: Trilha para a Costa Brava, 29.VI.1995, M.G.Bovini 841 et al., fr. (RB); Parati, transição manguerestinga-mata de encosta, 07.VII.1989, C.Farney 2337 et al., fr. (RB).

Material adicional examinado: São Paulo: Cananéia, Ilha do Cardoso: margem do rio Sítio Grande, 09.VI.1983, F.Barros 844, fr. (IAC, $\mathrm{SP}$ ); margem do rio Sítio Grande 03.XI.1978, M.A.V.Cruz 15 et al., fl. fem. (UEC); restinga de Itacuruçá, 18.X.1978, D.A.De Grande 128 et al., fl. masc. (IAC, SP); manguezal no rio Perequê, 5.X.1987, A.M.Giulietti 1051, fl. fem.;
(SPF); margem do rio Perequê, 25.X.1989, M.C.H.Mamede 194 et al., fl. masc.IAC, SP).

8. Rapanea lineata Mez, in Engler, Das Pflanzenreich 4. 236 (Heft 9):385. 1902.

Arbusto até árvore (1,2-) 2,0-3,0 $(-8,0) \mathrm{m}$ alt.; ramos (1,1-) 2,0-2,7 (-3,2) mm diâm., glabros. Pecíolo (0,4-) 0,5-0,8 (-1,1) cm compr.; lâmina $(6,4-) 8,0-11,4(-16,4) \mathrm{cm}$ compr., (1,5-) 2,4-3,2 (-4,5) cm larg., membranácea, glabra, oblanceolada, às vezes assimétrica em relação à nervura mediana, base e ápice agudos, nervura mediana saliente na face dorsal, impressa na ventral, nervação secundária conspícua a inconspícua na face dorsal, pouco conspícua a inconspícua na ventral, terciária inconspícua na face dorsal, conspícua a inconspícua na ventral, pontuações dispersas e canais resiníferos ordenados em linhas muito evidentes, que se estendem desde a nervura mediana em ângulo bem menor que o das nervuras secundárias, até a margem, apenas na face dorsal. Inflorescência 3,0-5,0 mm compr., axilar, umbelada, glabra. Flores 5(-4)-meras, unissexuadas, pedicelo 1,13,0 mm compr., glabro. Flor estaminada: cálice ca. 1,0 mm compr., ciliado, 1/5 unido, lobos 0,8 mm compr., 0,4 mm larg., oval-lanceolados ou triangulares, ápice acutiúsculo; corola ca. 2,8 mm compr., ciliada, esverdeada a branca, 1/6 unida, lobos 2,3 mm compr., 1,0 mm larg., patentes, lanceolados, ápice agudo; anel estaminal ausente, antera séssil, ca. $1,3 \mathrm{~mm}$ compr., unida à pétala na $1 / 2$ basal, triangular a sagitada; pistilódio ca. 1,0 mm compr., estreitamente cônico. Flor pistilada: cálice ca. $1,2 \mathrm{~mm}$ compr., ciliado, 1/6 unido, lobos $1,0 \mathrm{~mm}$ compr., 1,0 mm larg., largo-ovais, ápice agudo; corola ca. 2,4 mm compr., ciliada, esverdeada a branca, $1 / 3$ unida, lobos $1,8 \mathrm{~mm}$ compr., $0,8 \mathrm{~mm}$ larg., patentes ou deflexos, elípticos, ápice agudo; anel estaminoidal ausente, antera vestigial ca. 1,0 mm compr., sagitada; ovário ca. 1,2 mm compr., 0,7 mm diâm., elipsoidal, estigma séssil, ca. 1,3 mm compr., 3-fido, estreitamente cônico-verrucoso. Fruto ca. 5,0 $\mathrm{mm}$ alt., 5,0 $\mathrm{mm}$ diâm., esférico, roxo- 
nigrescente; semente ca. 3,0 mm alt., 4,8 mm diâm., oblata.

Nomes vulgares: Capororoca-mineira (Mez, 1902; Corrêa, 1926) e sobro (Corrêa, 1926).

Dados fenológicos, ecológicos e de distribuição: Observada com flores em novembro. A espécie é encontrada em Floresta Ombrófila Densa, a 600-1900m s.m., frequientemente em locais úmidos, como beira de rios; espécie ciófila a semi-heliófila, até heliófila. Ocorre de Minas Gerais até o Rio Grande do Sul, no eixo norte-sul e do litoral até Mato Grosso no eixo leste-oeste.

Comentários: O material Glaziou 8792 (R), por nós examinado é um dos materiais da coleção citada por Mez (1902) na descrição original de $R$. lineata, tratando-se de um síntipo. No material da APA - Cairuçu, a nervação secundária e terciária é conspícua.

Material examinado: APA-Cairuçu: Morro do Cuscuzeiro, mata de encosta entre 600 e 1200m s.m., 20.XI.1990, C.Farney 2473 \& M.Nadruz, fl. fem. (IAC, RB).

Material adicional examinado: Minas Gerais: Itatiaia, lado do Rio Preto, 22.XI.1876, Glaziou 8792, fl. masc. (R); São Paulo: Bananal, Serra da Bocaina, próximo ao marco 22, a 1150m s.m., 23.VI.1978, G.Martinelli 4676, fl. fem., fr. (IAC, RB); ibidem, Serra da Bocaina, alto do Morro da Antena, 28.IX.1994, E.A.Rodrigues 229 et al., fl. masc. (IAC, SP); Biritiba-Mirim, Estação Biológica de Boracéia, 890-950m s.m., 14.XI.1983,A.Custódio Filho 1842, fl. fem. (IAC, SP, SPSF).

\section{DISCUSSÃO E CONCLUSÕES}

As Myrsinaceae constituem uma família com relativamente grande diversidade no Rio de Janeiro, sendo que, na APA - Cairuçu, cerca de $60 \%$ das famílias têm menos gêneros e $70 \%$ menos espécies do que elas. Ocorrem em vários tipos de ambientes, desde a floresta primária até áreas em sucessão florestal ou campos e outras vegetações abertas. $\mathrm{Na}$ floresta primária podem ocorrer tantas ou mais espécies que em floresta secundária, mas nesta última, tal como em topo de morro, freqüentemente apresentam maior número de indivíduos, podendo ser elemento de destaque na fisionomia (Pessoa et al., 1997, GuedesBruni et al., 1997).

Das espécies ocorrentes na APA Cairuçu, $R$. ferruginea habita a floresta ombrófila de terras baixas, a submontana, a floresta secundária e áreas antropizadas, tais como beira de estrada. As outras espécies são mais seletivas, predominando nas florestas ombrófilas. Rapanea guyanensis e $R$. parvifolia ocorrem também em vegetações com influência marinha (restinga) ou fluviomarinha (mangue).

Algumas Myrsinaceae, ocorrentes na APA - Cairuçu, $R$. ferruginea, $R$. lineata e C. peruvianus, têm ampla distribuição no Brasil ou América do Sul, tendo sido amostradas também em outras áreas do Rio de Janeiro (Siqueira 1993, Freitas \& Kinoshita 1999). Outras, A. depauperata e A. martiana, são endêmicas regionais, tendo sido registradas apenas no Rio de Janeiro e São Paulo.

Os dados fenológicos sobre as Myrsinaceae são muito escassos. No geral, a floração e frutificação ocorrem em períodos limitados do ano, e estes períodos, observados na APA - Cairuçu, encontram-se dentro daqueles observados para São Paulo (observação pessoal). Entretanto, $R$. ferruginea foi observada em floração e frutificação em períodos limitados e essencialmente coincidentes na APA - Cairuçu e em Macaé de Cima (Freitas comunicação pessoal), mas em São Paulo foram observadas em floração e frutificação praticamente durante o ano todo. Ardisia depauperata foi observada em floração em novembro na APA - Cairuçu, um mês antes, em relação a São Paulo.

Atualmente, uma série de alterações taxonômicas tem sido adotadas ou propostas em relação às Myrsinaceae. Agostini (1980) propôs uma nova classificação, ampliando o conceito e sinomizando vários gêneros a Cybianthus, e estabeleceu dez subgêneros: 
Comomyrsine, Conomorpha, Cybianthopsis, Cybianthus, Iteoides, Laxianthus, Microconomorpha, Stapfia, Triadophora e Weigeltia. Pipoly (1987) sinonimizou o gênero Grammadenia em Cybianthus, considerandoo também como um subgênero. Pipoly (1998), sinomimizou o subgênero Iteoides em Microconomorpha. Ståhl (1997) incluiu Conomorpha e Grammadenia em seus estudos cladísticos e constatou que a maioria das análises não suportava a circunscrição ampla de Cybianthus. Embora tenhamos aceito a delimitação ampla de Cybianthus, não temos subsídios para avaliar se a delimitação é adequada ou se as espécies, por nós tratadas, pertenceriam a gêneros distintos, já que as análises de Ståhl (1997) não incluíram todos os subgêneros. De acordo com a conceituação de Agostini (1980), ocorrem no Estado do Rio de Janeiro o subgênero Conomorpha, representado por $C$. peruvianus, e o subgênero Cybianthus, representado por uma espécie provavelmente nova.

Anderberg \& Ståhl (1995) sugeriram afinidades entre Ardisia e Stylogyne, enquanto Pipoly (1996b) sugeriu a necessidade de reavaliação, das delimitações genéricas, na tribo Ardiseae, observando que em estudos das espécies americanas era usual a criação de novos gêneros a partir de Ardisia enquanto para as espécies de outras áreas ocorria o contrário, ou seja, a sinonimização de vários gêneros em Ardisia. Ståhl (1997) evidenciou, através de análise cladística, afinidades entre Ardisia e Stylogyne e concluiu que a condição pauciovulada evoluiu, a partir de uma condição multiovulada, independentemente, em mais do que uma ocasião. Bernacci \& Jung-Mendaçolli (2000) concluíram que espécies de Stylogyne deveriam ser incluídas em Ardisia por terem constatado que as características utilizadas para a distinção dos dois gêneros, como corola contorta e placenta em uma única série de óvulos, ocorriam tanto em um como no outro gênero.

Pipoly (1996a), em função da análise das características estaminais de dez espécies recentemente descritas (Pipoly 1991, 1992a e b), propôs a sinonimização do gênero Rapanea a Myrsine, conforme os argumentos delineados a seguir: presença de táxons em que os filetes são totalmente livres entre si e dos lobos da corola; outros em que os filetes são curtamente conatos basalmente, porém, livres da face adaxial da corola; outros por sua vez têm filetes parcialmente conados, porém, totalmente adnatos à face adaxial do tubo da corola e superfície dos lobos e, finalmente aqueles em que a porção basal dos filetes forma um tubo ontogeneticamente fundido ao tubo da corola, bem como a porção superior destes filetes, ontogeneticamente fundidos aos lobos da corola. Entretanto, não entendemos onde reside a diferença entre filetes parcialmente unidos entre si e completamente adnados ao tubo e lobos da corola em relação a filetes com a porção inferior formando um tubo ontogeneticamente fundido ao tubo da corola e porção superior fundida ontogeneticamente aos lobos da corola.

Por outro lado, apesar de Pipoly (1996a) mencionar a existência de filetes livres da corola em espécies recentemente descritas (Pipoly 1991, 1992a e b), isto não está claramente apontado nas descrições e, através das ilustrações, apenas a espécie peruana Myrsine minutiflora Pipoly (1992c), talvez pudesse representar uma das condições referidas por Pipoly (1996a), como tendo filetes livres da corola (filetes totalmente livres entre si e dos lobos da corola ou filetes curtamente conatos basalmente, porém, livres da face adaxial da corola). Embora Pipoly (1996a) não tenha mencionado a referência a Pipoly (1992c), isto pode ter ocorrido por lapso, uma vez que Pipoly (1996a) mencionou a análise de espécies peruanas.

Pipoly \& Ricketson (1999) consideraram que Ardisia também teria filetes livres do tubo da corola, o que inclusive caracterizaria o maior gênero da família e permitiria a sua distinção de gêneros próximos. Entretanto, outros autores, tais como Mez (1902) e Lundell (1971), consideram Ardisia como tendo filetes unidos 
à corola. Ainda como exemplos, Mez $1902 \mathrm{e}$ Lundell, 1971 consideraram que a família Myrsinaceae tem como característica filetes unidos à corola, mesmo que chegando a ser quase livres, em alguns casos. De acordo com Cronquist, todas as famílias da ordem Primulales apresentam filetes, ao menos parcialmente, unidos à corola. Judd et al. 1999 fizeram a mesma consideração, considerando a subordem Primulinae.

Mez (1902) restringiu Myrsine a dez espécies atuais da África e Ásia e vinte fósseis, enquanto Rapanea seria constituído por duzentas espécies atuais e teria ocorrência pantropical. Smith (1973) aceitou a circunscrição proposta por Mez (1902) para Myrsine e chamou atenção para a existência de um anel estaminal fundido à corola apenas na base, no ápice do qual os filetes tornam-se livres entre si. A fusão dos filetes à corola apenas parcialmente (condição pleisiomórfica) e o registro fóssil podem ser interpretados como evidência da origem evolutivamente anterior de Myrsine em relação a Rapanea. A interpretação da morfologia das espécies recém-descritas por Pipoly (1991, 1992a, b e c) implica na necessidade da análise dos materiais por ele examinados, o que não foi possível até o momento.

\section{AGRADECIMENTOS}

Agradecemos à MS Maria de Fátima Freitas (Universidade Estadual Paulista, Campus Assis) cuja participação no estudo de Rapanea no projeto "Flora Fanerogâmica do Estado de São Paulo" vem somando esforços para o conhecimento deste grupo taxonômico.

\section{REFERÊNCIAS BIBLIOGRÁFICAS}

Agostini, G. 1980. Una nueva clasificación del género Cybianthus (Myrsinaceae). Acta Botanica Venezuelica 10 (2): 129185.

Andenberg, A.A. \& Ståhl. 1995. Phylogenetic interrelationships in the order Primulales, with special emphasis on the family circumscriptions. Can. J. Bot. 73: 1699-4730.
Aublet, J.B.C. F. 1775. Histoire des plantes de la Guiane Françoise. Paris, PierreFrançois Didot, v. 1-4, 976p, 392 est.

Bernacci, L.C. \& Jung-Mendaçolli, S.L. 2000. Considerações taxonômicas e novas combinações em Ardisia Swartz (Myrsinaceae) do sudeste do Brasil. Acta bot. bras. 14(3): 243-249.

Corrêa, M.P. 1926. Dicionário das plantas úteis do Brasil e das exóticas cultivadas. Rio de Janeiro, Imprensa Nacional, v. 1, 747p.

Corrêa, M. P. 1931. Dicionário das plantas úteis do Brasil e das exóticas cultivadas. France, Imprimerie Crété Corbeil, v. 2, 707p.

Cronquist, A. 1968. The evolution and classification of flowering plants. Boston, Houghton Mifflin. 396p.

Cronquist, A. 1981. An integrated system of classification of flowering plants. New York, Columbia University, 1262p.

De Candolle, A. 1841. Second mémoire sur la famille des Myrsineacées. Ann. Sci. Nat., sér. 2 (16): 65-97, 3 est.

De Candolle, A. 1841. Troisième Mémoire sur la familie des Myrsinéacées. Ann. Sci. Nat. Ser. 2 (16): 9-176.

Fonnegra-Gómez, R.J. 1985. Palinologia da família Myrsinaceae R. Br. no Brasil. Tese de Doutorado, Instituto de Biociências, Universidade de São Paulo. São Paulo, 220p.

Freitas, M.F. \& Kinoshita, L.S. 1999. Reserva Ecológica de Macaé de Cima, Nova Friburgo, RJ: Myrsinaceae. $50^{\circ}$ Congresso Nacional de Botânica, Resumos: 69. Blumenau.

Guedes - Bruni R. R., Pessoa, S.V.A. \& Kurtz, B.C. 1997. Florística e estrutura do componente arbustivo-arbóreo de um trecho preservado de floresta montana na Reserva Ecológica de Macaé de Cima. In: Lima, H.C. \& Guedes-Bruni, R. R. (eds.) Serra de Macaé de Cima: diversidade florística e conservação em mata atlântica. p.125-145. Instituto 
de Pesquisas Jardim Botânico do Rio de Janeiro.

Hoehne, F.C., Kuhlmann, M. \& Handro, O. 1941. O Jardim Botânico de São Paulo. São Paulo. Empresa Gráfica da "Revista dos Tribunais" Ltda., 656p.

Judd, W.S., Campbell, C.S., Kellog, E.A. \& Stevens, P.F. 1999. Plant systematics: a phylogenetic approach. Sunderland, Sinauer Associates, 464p.

Jung-Mendaçolli, S.L. \& Bernacci, L.C. 1997a. Myrsinaceae. In: Marques, M.C.M. Mapeamento da cobertura vegetal e listagem das espécies ocorrentes na área de proteção ambiental de Cairuçu, Município de Parati, RJ: Série Estudos e Contribuições 13: 72.

Jung-Mendaçolli, S.L. \& Bernacci, L.C. 1997b. Flora Fanerogâmica da Ilha do Cardoso (SP, Brasil): Myrsinaceae. Flora Fanerogâmica da Ilha do Cardoso 5: 81-98.

Lundell, C.L. 1971. Myrsinaceae. Flora of Panama. Part VIII. Ann. Missouri Bot. Gard. 58: 285-354.

Marques, M.C.M. (org.). 1997. Mapeamento da cobertura vegetal e listagem das espécies ocorrentes na Área de Proteção Ambiental de Cairuçu, Município de Parati, RJ. Série Estudos e Contribuições 13: 1-96.

Marques, M.C.M., Vaz, A.S.F. \& Marquete, R. (org.). 1997. Flórula da APA Cairuçu, Parati, RJ: espécies vasculares. Série Estudos e Contribuições 14: 1-576.

Mez C. 1901. Myrsinaceae. In: Urban, I. Symbolae Antillanae. Leipzig, Borntraeger, v.2, p. 397-500.

Mez, C. 1902. Myrsinaceae.In: Engler, H.G.A. Das Pflanzenreich. Berlin, Wilhelm Engelmann, v. 4 - 236 (9) p. 1-437.

Miquel, F.A.G. 1856. Myrsineae. In: Martius, C. F. P. von; Eichler, A. W. \& Urban, I. Flora Brasiliensis, München, Wien, Leipzig, Monachii, Typografia Regia, v.10, p.269-338, est.24-59.
Pessoa, S.V.A., Guedes-Bruni, R.R. \& Kurtz, B.C. 1997. Composição florística e estrutura do componente arbustivoarbóreo de um trecho secundário de floresta montana na Reserva Ecológica de Macaé de Cima. In: Lima, H.C. \& Guedes-Bruni, R.R. (eds.) Serra de Macaé de Cima: diversidade florística e conservação em mata atlântica. p.147-167. Instituto de Pesquisas Jardim Botânico do Rio de Janeiro.

Pipoly, J.J. 1981. Contributions toward a monograph of Cybianthus (Myrsinaceae): I. subgenus Iteoides and the identity of Conomorpha loretensis. Brittonia 33(4): 493-497.

Pipoly, J.J. 1983. Contributions toward a monograph of Cybianthus (Myrsinaceae): III. a revision of subgenus Laxiflorus. Brittonia 35(1): 61-80.

Pipoly, J.J. 1987. A systematic revision of the gass Cybianthus subgenus Grammadenia (Myrsinaceae). Mem. of the New York Bot. Gard. 43: 1-76.

Pipoly, J.J. 1991. Systematic studies in the genus Myrsine (Myrsinaceae) in Guayana. Novon 1: 204-210.

Pipoly, J.J. 1992a. A further note on Myrsine perpauciflora Pipoly (Myrsinaceae). Novon 2(2): 176.

Pipoly, J.J. 1992b. Estudios en el género Myrsine (Myrsinaceae) de Colombia. Caldasia 17(1): 3-10.

Pipoly, J.J. 1992c. Notes on the genus Myrsine (Myrsinaceae) in Peru. Novon 2(4): 392-407.

Pipoly, J.J. 1996a. Contribution toward a new flora of the Philippines: I. a synopsis of the genus Myrsine (Myrsinaceae). Sida 17(1): 115-162.

Pipoly, J.J. 1996b. New species of Ardisia (Myrsinaceae) from Ecuador and Peru. Sida 17 (2): 445-458.

Pipoly, J.J. 1998. The genus Cybianthus (Myrsinaceae) in Ecuador and Peru. Sida 18(1): 1-60. 
Pipoly, J.J. \& Ricketson, J.M. 1999. Discovery of the Indo-Malasian genus Hymenandra (Myrsinaceae) in the neotropics and its boreotropical implications. Sida 18(3): 701-746.

Ruiz, H. \& Pavon, J. 1798. Systema vegetabilium florae peruvianae et chilensis. Madrid, 250p.

Siqueira, J.C. 1993. O gênero Rapanea Aublet (Myrsinaceae) na região serrana do Estado do Rio de Janeiro: aspectos taxonômicos e ecológicos das espécies. Pesquisas (Botânica) 44: 41-52.

Smith, A.C. 1973. Studies of pacific islands plants, XXV: the Myrsinaceae of the Fidjian region. Jour. Arn. Arb. 54: 228292.

Smith, L. B. \& Downs, R. J. 1957. Resumo preliminar das mirsináceas de Santa Catarina. Sellowia 8: 237-248, 4 est.

Ståhl, B. 1997. The relationships of Heberdenia bahamensis and $H$. peduliflora (Myrsinaceae). Bot. J. Linn. Soc. 122: 315-333. 